Review

\title{
Crossing the Border: Molecular Control of Motor Axon Exit
}

\section{Arlene Bravo-Ambrosio ${ }^{1}$ and Zaven Kaprielian ${ }^{1,2, *}$}

1 Dominick P. Purpura Department of Neuroscience, Albert Einstein College of Medicine, Bronx, NY 10461, USA; E-Mail: Arlene.Bravo@med.einstein.yu.edu

2 Department of Pathology, Albert Einstein College of Medicine, Bronx, NY 10461, USA

* Author to whom correspondence should be addressed; E-Mail: Zaven.Kaprielian@einstein.yu.edu; Tel.: +1-718-430-2162; Fax: +1-718-430-3758.

Received: 17 October 2011; in revised form: 5 November 2011 / Accepted: 8 November 2011 / Published: 29 November 2011

\begin{abstract}
Living organisms heavily rely on the function of motor circuits for their survival and for adapting to ever-changing environments. Unique among central nervous system (CNS) neurons, motor neurons (MNs) project their axons out of the CNS. Once in the periphery, motor axons navigate along highly stereotyped trajectories, often at considerable distances from their cell bodies, to innervate appropriate muscle targets. A key decision made by pathfinding motor axons is whether to exit the CNS through dorsal or ventral motor exit points (MEPs). In contrast to the major advances made in understanding the mechanisms that regulate the specification of MN subtypes and the innervation of limb muscles, remarkably little is known about how MN axons project out of the CNS. Nevertheless, a limited number of studies, mainly in Drosophila, have identified transcription factors, and in some cases candidate downstream effector molecules, that are required for motor axons to exit the spinal cord. Notably, specialized neural crest cell derivatives, referred to as Boundary Cap (BC) cells, pre-figure and demarcate MEPs in vertebrates. Surprisingly, however, BC cells are not required for MN axon exit, but rather restrict $\mathrm{MN}$ cell bodies from ectopically migrating along their axons out of the CNS. Here, we describe the small set of studies that have addressed motor axon exit in Drosophila and vertebrates, and discuss our fragmentary knowledge of the mechanisms, which guide motor axons out of the CNS.
\end{abstract}

Keywords: motor axon exit; axon pathfinding; spinal cord; motor exit point; dorsally-exiting motor neuron; ventrally-exiting motor neuron; Nkx2.9; Robo; Slit 


\section{Introduction}

Mammals rely on motor neurons (MNs) to transmit information from the central nervous system (CNS) to our peripheral organs and somatic muscles, to establish autonomic control of visceral functions and to coordinate musculoskeletal movement, respectively. Unique among all other classes of CNS neurons, axons of developing MNs establish such connections by breaching the basal lamina surrounding the neural tube and emerging from the confines of the CNS. Just like cars traveling on a freeway, motor axons must ultimately exit to reach their final destination. Just as exit signs are positioned on freeways, motor axon exit points are located at well-defined positions along the margin of the CNS. However, breaks in the basal lamina at these positions that would facilitate motor axon exit, analogous to exit ramps for cars, have not been described. Accordingly, how MN axons cross the CNS:PNS interface remains a major unanswered question.

Once in the periphery, MN axons follow a stereotypical trajectory to synapse with muscle targets. Defined by their particular muscle targets, MNs are classified into three categories: (i) somatic MNs, which directly innervate skeletal muscle; (ii) specific classes of visceral MNs, also known as branchiomotor neurons, which directly innervate branchial (pharyngeal) arch-derived muscles; and (iii) generic visceral $\mathrm{MNs}$, which indirectly innervate cardiac/smooth muscles or various glands. Despite the significant progress made in elucidating mechanisms that regulate $\mathrm{MN}$ subtype diversification, motor axon guidance to specific muscle targets, and the formation of sensory-motor connections, how motor axons leave the CNS remains a poorly understood phenomenon. In this review, we will focus on one of the most important, but poorly understood aspects of $\mathrm{MN}$ development - molecular mechanisms that control the projection of motor axons towards and out of the CNS - but we begin by describing the development of both somatic and branchial MNs, highlighting the cellular and molecular mechanisms that specify these particular classes of MNs.

\section{Motor Neuron Subtypes: Dorsally- and Ventrally-Exiting Motor Neurons}

Motor neuron subtypes are categorized by the settling positions of their cell bodies and the trajectories that their axons follow to exit the CNS. A particularly clear distinction among $\mathrm{MN}$ subtypes is the relative position of their exit points along the margins of the brainstem and spinal cord; ventrally- (vMNs) and dorsally- (dMN) exiting MNs extend through ventral and dorsal points, respectively (Figure 1) [1-8]. Insights from vertebrate evolution may explain why MN axons project through either dorsal or ventral motor exit points. In primitive chordates such as amphioxus, axons of MNs and Rohon Beard sensory neurons project through dorsal exit points within the spinal cord [9]. As vertebrates such as the lamprey emerged, vMNs replaced those that exited at more dorsal positions within the spinal cord. However, axons of cranial MNs located within the vertebrate hindbrain retained their ancestral trajectory and emerged from the CNS at dorsal exit points [9]. Notably, in mouse embryos, the state of Cxcl12-Cxcr4 signaling appears to facilitate the projection of vMN axons to ventral as opposed to dorsal exit points (Table 1) [6]. Although speculative, the evolution of this ligand-receptor pair (Cxc112-Cxcr4), across vertebrates may provide insights into why and how subtypes of motor axons grow towards precisely positioned exit points. 
Figure 1. Motor neuron subtypes and the projections of their axons out of the CNS. (A) Schematic of motor neuron nuclei in the developing brainstem (rhombomere (r), r1 to r7) and spinal cord. vMNs are indicated in red on the left, whereas dMNs are indicated in blue on the right of the schematic. Trigeminal (V) motor nuclei are shown in purple. Each cranial motor nuclei is numbered in roman numerals, e.g., CN XI. Abbreviations: fp, floor plate; sMN, spinal motor neuron; (B) Axonal projections of vMNs in the hindbrain (VI, XII) and spinal cord (sMN) are shown in red; (C) Axonal projections of dMNs (VII, IX, X, XI) and trigeminal (V) dMNs are shown in blue and purple, respectively. Note that axons extending from trigeminal dMNs avoid sensory ganglia (white ovals), while axons of other $\mathrm{dMN}$ invade these ganglia [6].

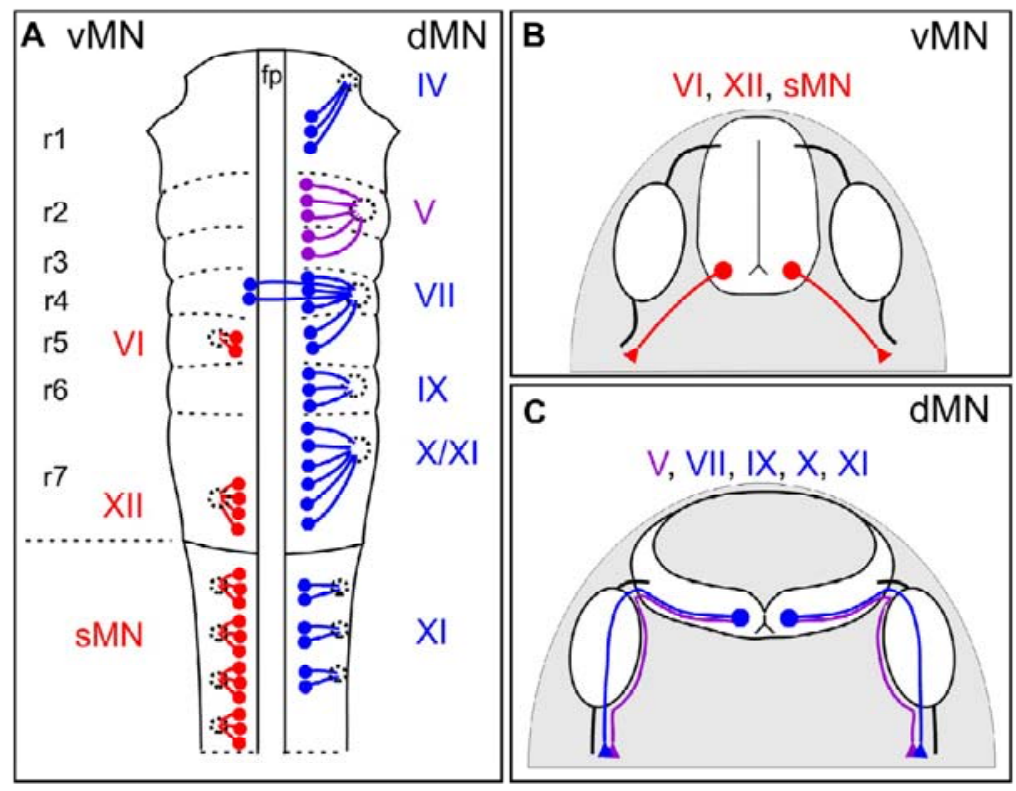

Table 1. Molecules localized to motor exit points and/or required for motor axon exit.

\begin{tabular}{|c|c|c|c|}
\hline Name & Organism & Localization & Role in motor neuron development \\
\hline Cxcl12 & Mouse & mesenchyme & $\begin{array}{l}\text { Required for a subset of vMN axons to exit } \\
\text { through ventral exit points[6] }\end{array}$ \\
\hline Cxcr4 & Mouse & vMN & $\begin{array}{l}\text { Required for a subset of vMN axons to exit } \\
\text { through ventral exit points[6] }\end{array}$ \\
\hline Eve $(\mathrm{TF})$ & Drosophila & $\mathrm{dMNs}$ & Required for dMN axons to exit the CNS[10] \\
\hline LH3 (diwanka) & Zebrafish & myotome & $\begin{array}{l}\text { Promotes the exit of a subset of } \mathrm{MN} \text { axons } \\
\text { from the CNS[11,12] }\end{array}$ \\
\hline $\operatorname{Lhx} 3 / \operatorname{Lh} \times 4(\mathrm{TF})$ & Mouse & vMNs & $\begin{array}{l}\text { Required for vMN specification; sufficient to } \\
\text { re-direct dMN axons to and through ventral } \\
\text { exit points[4] }\end{array}$ \\
\hline Myosin II & Chick & growth cone & $\begin{array}{l}\text { Required for a subset of dMN axons to project } \\
\text { towards their appropriate motor exit point[13] }\end{array}$ \\
\hline Nkx6 (TF) & Drosophila & vMNs & Required for vMN axons to exit the CNS[14] \\
\hline Nkx2.9 (TF) & Mouse & $\begin{array}{l}\text { SACMN derived } \\
\text { from } \mathrm{Nkx} 2.9 \\
\text { progenitors }\end{array}$ & Required for SACMN axon exit * \\
\hline
\end{tabular}


Table 1. Cont.

\begin{tabular}{|c|c|c|c|}
\hline Npn1a & Zebrafish & $\mathrm{CaP} \mathrm{MN}$ & $\begin{array}{l}\text { Required for the proper positioning of motor } \\
\text { exit points[15] }\end{array}$ \\
\hline Npn2 & Chick/Mouse & vMN cell bodies & $\begin{array}{l}\text { Required for the confinement of vMN somata } \\
\text { to the CNS [16] }\end{array}$ \\
\hline $\begin{array}{l}\text { Phox } 2 a / \text { Phox } 2 b \\
\text { (TF) }\end{array}$ & Chick & dMNs & $\begin{array}{l}\text { Sufficient to re-specify interneurons into } \\
\text { MNs[17] }\end{array}$ \\
\hline PlexinA1 & Chick & vMN axons & $\begin{array}{l}\text { Prevents vMN somata from inappropriately } \\
\text { migrating out of the CNS[18] }\end{array}$ \\
\hline PlexinA2 & Chick & vMN cell bodies & $\begin{array}{l}\text { Prevents vMN somata from inappropriately } \\
\text { migrating out of the CNS[16] }\end{array}$ \\
\hline $\begin{array}{l}\text { PlexinA3 } \\
\text { (sidetracked) }\end{array}$ & Zebrafish & $\begin{array}{l}\text { MiP and RoP } \\
\text { MNs }\end{array}$ & $\begin{array}{l}\text { Required for the proper positioning of motor } \\
\text { exit points[19] }\end{array}$ \\
\hline RhoA & Chick & growth cone & $\begin{array}{l}\text { Required for a subset of } \mathrm{dMN} \text { axons to project } \\
\text { towards their appropriate motor exit point[13] }\end{array}$ \\
\hline Robo2 & Mouse & SACMN axons & Required for SACMN axon exit * \\
\hline Sema3ab & Zebrafish & Somite & $\begin{array}{l}\text { Required for the proper positioning of motor } \\
\text { exit points[15] }\end{array}$ \\
\hline Sema6A & Chick/Mouse & BC Cells & $\begin{array}{l}\text { Prevents vMN somata from inappropriately } \\
\text { migrating out of the CNS }[16,18]\end{array}$ \\
\hline Slit1/Slit2 & Mouse & $\begin{array}{l}\text { Lateral exit } \\
\text { point-associated } \\
\text { cells }\end{array}$ & Required for SACMN axon exit* \\
\hline Zfh1 (TF) & Drosophila & vMNs & $\begin{array}{l}\text { Required for a subset of vMN axons to exit } \\
\text { the CNS[20] }\end{array}$ \\
\hline
\end{tabular}

The role (or proposed role) of these motor exit point- and motor axon exit-associated molecules is discussed in the text. Abbreviations: CaP, caudal primary $\mathrm{MN}$; dMN, dorsally-exiting motor neuron; MiP, middle primary MN; RoP, rostral primary MN; SACMN, Spinal Accessory Motor Neuron; TF, transcription factor; vMN, ventrally-exiting motor neuron. * Unpublished observations.

Both $\mathrm{dMN}$ and vMN subtypes are located in the developing brainstem and spinal cord and extend their axons to branchial arch-derived and skeletal muscles, respectively. Another distinguishing feature of $\mathrm{vMN}$ and $\mathrm{dMN}$ is the location of their cell bodies along the D-V axis of the hindbrain/spinal cord; vMN settle in more ventral positions, whereas dMN migrate dorsally and settle at dorsal locations along the D-V axis of the hindbrain/spinal cord. The majority of dMNs reside within the brainstem and include neurons whose axons form cranial nerves (CN) IV, V, VII, IX, X, XI (cranial component) (Figure 1) [7,8]. Collectively, these particular CN play an important role in controlling head, eye, jaw, and neck movement, feeding, speech, and facial expressions [7,8]. The sole dMN population within the spinal cord is spinal accessory motor neurons (SACMN). SACMN are the only spinal MNs whose axons emerge from a dorsally-positioned motor exit point termed the lateral exit point (LEP) and assemble into the spinal accessory nerve (SAN), which comprises the spinal component of CN XI and innervates a subset of neck and back muscles [2,3,5,21].

In addition to the positioning of their cell bodies and the trajectories that their axons follow to project out of the CNS, vMN and dMN can also be distinguished by the complement of transcription factors (TFs) they express. Branchiomotor neurons, a class of dMN, express the homeodomain TFs, Phox2a and 
Phox $2 b$, which are required for the proper specification of this particular MN subtype $([17,22]$ and data not shown). Consistent with its role in $\mathrm{dMN}$ differentiation, Phox $2 b$ is required for the development of branchiomotor neurons, including SACMN [17,22]. dMN also express the T-box transcription factor, Tbx20, which is required for proper cell body migration of cranial MNs within the vertebrate hindbrain [23]. In contrast, developing vMNs express neither Phox2b nor Tbx20 and, instead, selectively express the homeobox gene $\mathrm{Hb9}$ ([24] and data not shown). Hb9 has an essential role in maintaining the identity of postmitotic vMN; in mice lacking $\mathrm{Hb} 9$, vMNs are generated in normal numbers and on schedule, however, they subsequently acquire a V2 interneuron identity [24].

\section{Motor Axon Exit Points}

As noted above, motor neuron subtypes can be distinguished by the path that their axons take to exit the neural tube [25-27]. During embryonic development, motor exit points are prefigured by neural crest derivatives, referred to as boundary cap (BC) cells [16,18,28,29]. Boundary cap cells not only reside at vMN $[16,18,29]$ and $\mathrm{dMN}$ ([28] and data not shown), but also at sites through which sensory axons enter the spinal cord or the dorsal root entry zone [30]. Krox-20 [31,32], a TF that belongs to the zinc finger family, cadherin-7 (Cad-7), a cell surface adhesion molecule and a member of type II cadherins [33,34], C-Lingo-1 [35], erythropoietin receptor [36], and monoamine oxidase B [37], are each BC markers in mammals. Given that BC cells are strategically positioned at motor axon exit points, it seemed reasonable to suspect that these cells regulate exit point-related $\mathrm{MN}$ guidance events [28]. The role of BC cells at motor exit points was investigated using three different types of manipulations/model systems: (1) surgical ablation of neural crest cells in chick embryos; (2) Splotch (Pax3 mutant) mice embryos whose neural crest cells fail to delaminate from the trunk region of the neural tube [38-40]; (3) the selective ablation of Krox-20-expressing $\mathrm{BC}$ cells by targeting diphtheria toxin to the Krox20 locus [29]. Notably, in all three in vivo models, the absence of $\mathrm{BC}$ cells failed to disrupt the pathfinding of vMN axons but, remarkably, their cell bodies ectopically migrated out of the CNS [29].

Consistent with previous findings at ventral exit points [29], we have observed that Cadherin-7- and Krox-20-expressing BC cells reside outside of the spinal cord and adjacent to dorsal exit points, including the lateral exit point (LEP) in chick and mouse embryos, respectively (Figure 2 and data not shown). To assess the in vivo role of BC cells in SACMN development, we analyzed Krox $20^{D T}$ mouse embryos, by co-labeling transvserse cryosections with anti-BEN, a selective marker for SACMN, and anti-islet1 or anti-phox2a, which are markers for all MNs or branchiomotor neurons (dMN), respectively. This revealed that SACMN axon pathfinding toward, and out of the spinal cord through the LEP was unaltered in these Krox-20-expressing BC cell-lacking animals. Notably, however, a considerable number of BEN-/Islet1- and BEN-/Phox2a-labeled SACMN cell bodies migrated out of the spinal cord and accumulated within the SAN in Krox $20^{D T}$ embryos (data not shown), and we observed a corresponding decrease in the number of BEN-/Islet1- and BEN-/Phox2a-labeled SACMN within the spinal cord of these animals (data not shown). Taken together, our findings are consistent with the behavior of $\mathrm{vMN}$ neurons and their axons in the absence of ventral exit point-associated BC cells [29], indicating that these unique cells confine both vMN and $\mathrm{dMN}$ cell bodies to the spinal cord. 
Figure 2. Cadherin 7-expressing BC cells are located at both the lateral and ventral exit points in chick embryos. Cervical spinal cord-containing transverse cryosections derived from E4.5 chick embryos were doubled-labeled with either anti-Ben and anti-Laminin (Left) or anti-Cadherin 7 and anti-NF (Middle, Right), and the appropriate secondary antibodies. (Left) BEN is expressed by both SACMN and $\mathrm{VMN}$ at this developmental stage, the FP and the SAN, which is positioned outside and adjacent to the spinal cord. Anti-Laminin labeling demarcates the margin of the spinal cord. (Middle) Cadherin 7-expressing BC cells are located at both the LEP and VEP. In this panel, the SAN is labeled by anti-NF. (Right) A higher magnification view of the boxed area in the middle panel. SACMN, spinal accessory motor neurons; SAN, spinal accessory nerve; vMN, ventral motor neurons; FP, floor plate; LEP, lateral exit point; VEP, ventral exit point; BC cells, boundary cap cells. Scale bar in middle panel, $100 \mu \mathrm{m}$, applies to the left and middle panels. Scale bar in right panel, $50 \mu \mathrm{m}$.

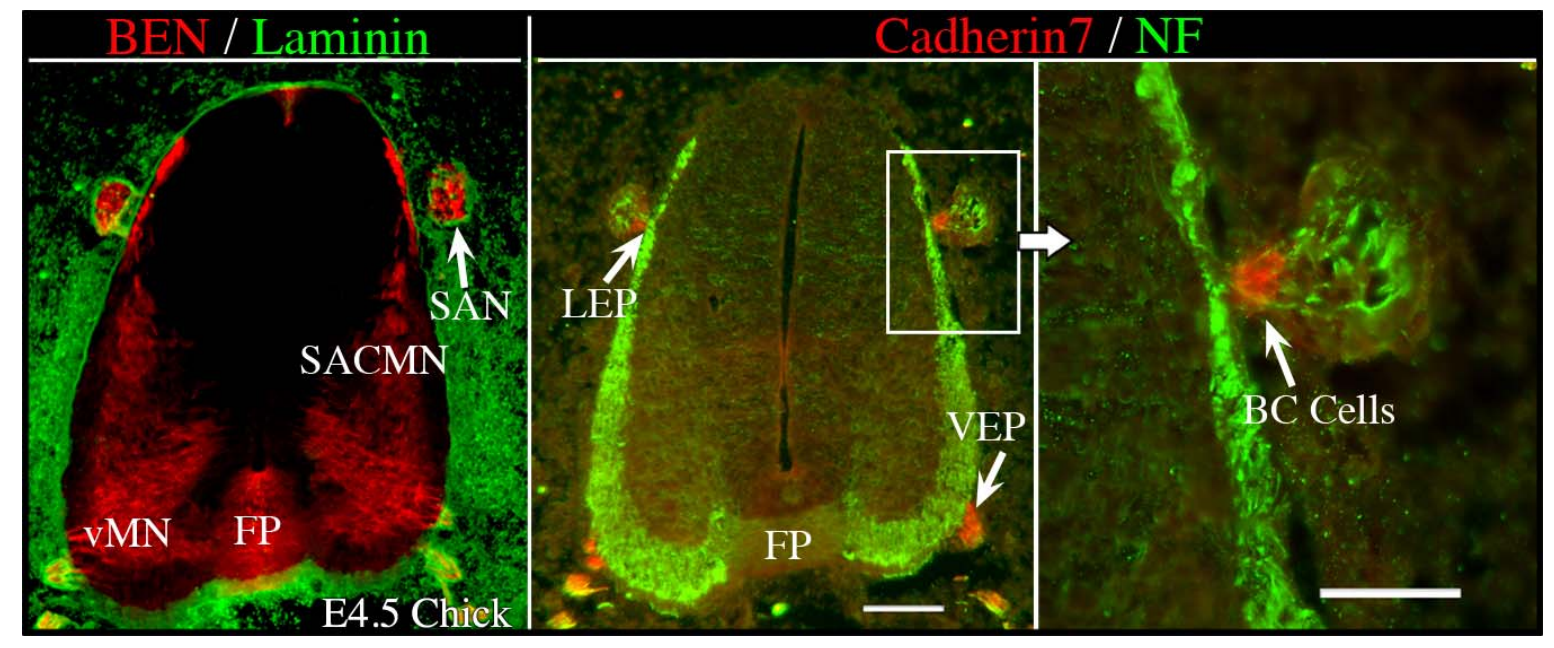

It has recently been established that BC cells confine vMN cell bodies to the vertebrate spinal cord through repulsive semaphorin-plexin interactions [16,18,41]. Specifically, selective knockdown of Neuropilin 2 in vMNs results in aberrant migration of their cell bodies out of the CNS along ventral nerve roots [16]. Consistent with these findings, vMN somata were observed at ectopic positions in the PNS of mice lacking Npn-2. Furthermore, BC cells express Sema6A, a transmembrane semaphorin, and Sema6A-deficient mice phenocopy Npn2 mutants, in that both exhibit an ectopic vMN cell body migration phenotype. Collectively, these interesting observations support a model in which semaphorinmediated repellent interactions between Neuropilin2-expressing vMNs and Sema6a-positive BC cells constrain vMN cell bodies to the CNS, by opposing the forces exerted by exiting vMN axons on their cell bodies (Table 1). Consistent with Sema6a's role in regulating vMN somata positioning, an independent study showed that Sema6a-PlexinA1 signaling is required for BC cells to cluster at the PNS/CNS border and, thus, prevents vMN cell bodies from inappropriately translocating out of the CNS (Table 1) [18].

Contrary to the observations that BC cells prefigure motor exit points, ultrastructural studies reveal that cellular features indicative of these cells are, in fact, not present at motor exit points just prior to the developmental stages when motor axons leave the CNS [42]. Specifically, electron microscopy (EM) failed to identify conspicuous clusters of morphologically unique cells at the CNS/PNS border 
(also referred to as the transition zone; TZ) in the vicinity of presumptive motor exit points within the hindbrain and spinal cord, when motor axons grow out of the vertebrate CNS. Instead, aggregates of these cells were only detected after motor axons leave the neuroepithelium and at considerable distances from exit points or the TZ $[42,43]$. These findings are in sharp contrast to observations made at sensory axon entry sites, where clusters of BC cells clearly prefigure these zones at the time when axons enter the CNS. In addition, EM micrographs revealed that an uninterrupted coat of basal lamina that covers a discontinuous layer of glial end-feet, which forms a thin barrier surrounding the neural tube termed the glial limitans, is associated with exit points, and gaps between glial end-feet at exit points are thought to facilitate the emergence of motor axons from the CNS (Figure 3) [42].

Figure 3. Electron micrograph of a section of neural tube derived from an E11 rat embryo at a presumptive motor exit point. A transverse section of the neural tube shows a thin layer of uninterrupted basal lamina that overlies glial end-feet, which form a conspicuous gap at a presumptive motor exit point. Black arrow, presumptive motor exit point; black asterisk, space found within presumptive white matter. Scale bar: $2 \mu \mathrm{m}$ [42].

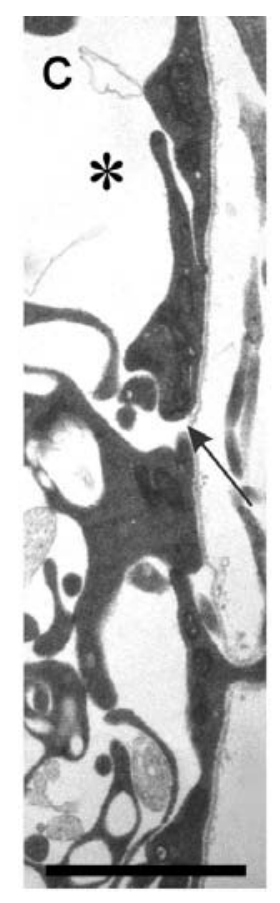

Since "gaps" between glial end-feet are strategically positioned at motor exit points, it seems possible that motor axons may project through these discontinuities to eventually exit the CNS. It is interesting to note in this regard that the complexity of SACMN growth cones is dramatically reduced such that they become slender and elongated as they reach their dorsally located exit point [3]. Such morphological changes in motor axon growth cones as they project out of the CNS would allow them to grow through small "gaps" formed by glial end-feet at motor exit points (see above).

\subsection{Motor Exit Point Chemoattractants}

A long held view has been that motor exit point-derived chemoattractants guide motor axons towards the positions at which they emerge from the CNS [29,44-47]. There are several lines of evidence 
supporting the existence of target (e.g., dermomyotome, limb bud, cranial sensory ganglia, branchial arches) derived chemoattractants for ventrally- and dorsally-exiting motor axons, including fibroblast growth factor (FGF) [48], hepatocyte growth factor (HGF) [46,49], and possibly ciliary neurotrophic factor (CNTF), brain-derived neurotrophic factor (BDNF), and cardiotrophin 1 (see [50]. The role of FGF as a dermomyotome-derived chemoattractant for a subclass of vMNs (MMCm) in vertebrates has been previously described [48]. A number of studies provide evidence that limb-derived mesenchymal tissue are capable of stimulating neurite outgrowth from spinal cord explants in vitro [51,52]. Although the identities of these chemoattractive forces are largely unknown, the vertebrate limb bud expresses candidate neurotrophic factors that support the survival of developing MNs and that may also stimulate the outgrowth of their axons. For example, limb bud derived-HGF attracts motor axons in vitro, however, motor axons are still capable of projecting to their target cells in HGF-deficient mice, raising the possibility that other (neurotrophic) chemoattractive factors co-exist and operate in a redundant manner within the developing limb. Consistent with this finding, antibodies to neurotrophins (NGF, BDNF, and NT-3) co-cultured with limb slices derived from mouse embryos revealed that these factors are required for the extension of motor axons to their associated limb targets [53]. Whether or not the target-derived chemoattractants described above are expressed at motor exit points remains to be determined and exit point-derived chemoattractants have yet to be identified for any subtype of MN. Nevertheless, studies in the embryonic chick hindbrain demonstrated that motor axons re-direct their growth and appropriately project towards their exit points after reversing the rostrocaudal polarity of particular rhombomeres [54]. In addition, both exit point-derived isthmic tissue, which normally expresses FGF8 mRNA, and FGF8 protein, is capable of attracting trochlear motor axons in vitro [55].

\subsection{Positioning of Motor Exit Points}

Motor exit points are segmentally reiterated along the rostrocaudal neural axis during embryonic development; however, our understanding of the mechanisms responsible for establishing their positions is fragmentary at best. Studies carried out in zebrafish embryos indicate that the sidetracked (set) gene, which was isolated from a genetic screen for molecules regulating motor axon pathfinding [56], has a role in positioning motor exit points (Table 1). In wild type zebrafish embryos, axons from three primary MNs: the caudal primary $(\mathrm{CaP})$, middle primary $(\mathrm{MiP})$, and rostral primary $(\mathrm{RoP})$, exit the spinal cord through a single exit point formed beneath the $\mathrm{CaP}$ cell body and located at the midpoint of the overlying somite. It is well-documented that $\mathrm{CaP}$ growth cones are the first to exit the spinal cord, pioneering a common path that is subsequently followed by MiP and RoP growth cones/axons [12]. Once all motor growth cones reach the distal end of this common path, also referred to as a choice point, they project along divergent paths to their target myotome regions. In contrast, sidetracked zebrafish mutants display dramatic motor axon exit defects; both MiP and RoP appropriately project in a caudal direction but bypass or extend rostrally away from their exit point, or even exit at ectopic positions directly beneath their cell bodies. Subsequently, it was shown that the gene disrupted in sidetracked mutants encodes the Semaphorin receptor, Plexin-A3 [19]. Using single-cell labeling and time-lapse microscopy, it was also shown that Plexin-A3 acts cell autonomously to direct MiP and 
RoP motor growth cones to their exit point, suggesting that posterior somite-derived semaphorins trigger repulsive Plexin-A3 signaling, which regulates MiP/RoP motor axon exit.

Additional findings from zebrafish embryos suggest that the positions of primary MN cell bodies prefigure motor exit points. As mentioned above, axons of primary neurons ( $\mathrm{CaP}, \mathrm{MiP}$, and RoP) exit the spinal cord immediately beneath the $\mathrm{CaP}$ cell body. Semaphorin-Neuropilin signaling plays an important role in establishing the proper positioning of $\mathrm{CaP}$ cell bodies and, consequently, motor exit points [15]; the position of $\mathrm{CaP}$, which expresses Neuropilin1a, was disrupted by antisense knockdown of Neuropilin1a and this gave rise to ectopic motor exit points. In complementary studies, knockdown of somite-derived Sema3ab, a class III semaphorin ligand for Neuropilin1a, resulted in an irregular distribution of $\mathrm{CaP}$ cell bodies and an increased number of ectopic motor axon exit points. Taken together, interactions between Neuropilin1a-expressing CaP MNs and somite derived-Sema3ab appear to be required for fine-tuning the position of $\mathrm{CaP}$ cell bodies.

CNS-derived glia, which ultimately form the perineurium that ensheaths and protects motor nerves, also prefigure motor axon exit points in Zebrafish embryos [57]. Specifically, in the absence of perineurial cells, which arise from ventral spinal cord-derived glia, MN axons exit the CNS at ectopic positions [57]. MN cell bodies were also observed to inappropriately migrate out of the spinal cord in the absence of CNS-derived perineural glia. Notably, mouse and chick embryos that lack neural crest-derived BC cells exhibit a similar phenotype (see above). Interestingly, in a separate study, it was shown that Zebrafish lacking neural crest cells do not display motor axon exit or MN cell body migration defects, like those observed in embryos lacking CNS-derived glia [58]. These particular observations suggest that, in zebrafish, neural crest cells are not required to confine MN somata to the CNS or for the appropriate projection of motor axons out of the spinal cord. Rather, perineurial cells appear to function as a barrier and regulate motor axon guidance at exit points in these vertebrates. In addition, Kucenas et al., 2009 observed that distinct interactions between progenitors of oligodendrocytes and Schwann cells, the myelinating cells of the CNS and PNS, respectively, prevent oligodendrocytes from migrating out of the spinal cord. Specifically, in the absence of peripheral Schwann cells, CNS-derived oligodendrocyte progenitors cross the CNS-PNS interface via ventral nerve roots and myelinate motor axons in the periphery. Taken together, these studies suggest that motor exit points are not only permeable to motor axons, but also to perineural glia cells, and that distinct mechanisms regulate the migration of MN/oligodendrocyte progenitor cell bodies and the guidance of motor axons at exit points.

\subsection{Signaling Molecules That Control the Projection of Motor Axons to Their Appropriate Exit Points}

The FP derived chemorepellents, Slits and Netrin-1, guide cranial motor axons along a dorsally-directed trajectory away from the ventral midline and toward their dorsal exit points, however, the downstream signaling mechanisms remain largely unknown [5,21,59-61]. Recent studies utilized a combination of in vitro and in vivo approaches to identify molecular components of Slit and Netrin-1 signaling pathways in the context of motor axon pathfinding. Specifically, it was shown that Slit and Netrin-mediated growth cone repulsion depends on retrograde actin flow [13], a process through which actin filaments are constantly being transported from the leading edge by myosin motors including myosin II (reviewed by [62]). Furthermore, Slit and Netrin-1 signaling is mediated by 
RhoA-kinase (ROCK) and myosin light chain kinase (MLCK), which positively regulate myosin II function by phosphorylating myosin II regulatory light chain (MRLC) [13]. Inhibition of ROCK, MLCK or myosin II in motor explant cultures produces a number of cranial motor axon pathfinding errors, including the inability of these axons to project away from the FP and their aberrant projection into the ventral midline. In complementary studies, genetic manipulation of RhoA, a GTPase protein that activates ROCK or myosin II in chick embryos results in cranial motor axon pathfinding errors, consistent with a loss of FP-mediated repulsion. In addition, de-regulation of RhoA and myosin II function in vivo results in branchiomotor axons mis-projecting away from or towards appropriate or incorrect motor exit points, respectively (Table 1). Taken together, these particular findings suggest that RhoA and myosin II are required for $\mathrm{dMN}$ axons to navigate towards their appropriate dorsal motor exit points.

\section{Motor Axon Exit}

\subsection{Projecting into the Periphery}

The initial pathfinding of motor axon growth cones from the CNS to the periphery requires extrinsic guidance cues, yet their identities are only beginning to be identified. The zebrafish diwanka gene appears to control this early stage of motor axon pathfinding $[12,63]$. In diwanka mutants, primary MN growth cones fail to project along a stereotypical route from the spinal cord to somites, raising the possibility that myotome-derived cues delineate this path (Figure 4 and Table 1). Notably, 40\% of primary MN axons fail to exit the spinal cord in diwanka mutants, suggesting that environmental cues in the periphery promote motor axon exit for a subset of primary MNs. The diwanka gene encodes LH3, a myotomally-derived glycosyltransferase, that acts through myotomal type XVIII collagen, a ligand for neural-receptor protein tyrosine phosphatases, which are known to control motor axon pathfinding [11]. These studies propose that LH3 (diwanka) catalyzes the addition of a sugar residue to a substrate protein, in this case, type XVIII collagen expressed by myotomal cells. Presumably, these diwanka-modified proteins are subsequently secreted from the myotome and deposited along the common motor pathway where they are capable of signaling motor axon growth cones to exit the spinal cord and pioneer into the periphery. 
Figure 4. diwanka is required for motor axon exit in zebrafish embryos. (A-D): Wild-type axonal projections of $\mathrm{CaP}(\mathbf{A}), \mathrm{MiP}(\mathbf{B})$, and $\mathrm{RoP}(\mathbf{C})$ primary MNs labeled with fixable dyes as previously described [12]. White arrows indicate the lower half of the spinal cord, which is out of the focal plane, whereas black arrows indicate the choice point, the distal end of a common path followed by $\mathrm{CaP}$, MiP, and RoP motor growth cones prior to their divergence into ventral, dorsal and medial myotomal regions, respectively $(\mathbf{D}) ;(\mathbf{E}-\mathbf{H})$ : In diwanka mutants, $\mathrm{CaP}(\mathbf{E})$ and $\operatorname{MiP}(\mathbf{F})$ axons extend wild-type projections within the spinal cord, however they exhibit abnormal projections along the common path (black arrow). Notably, the majority of RoP axons fail to exit the spinal cord in diwanka mutants and instead extend their axons caudally within the CNS (black arrowhead points to a RoP growth cone) $(\mathbf{G}, \mathbf{H})[12]$.

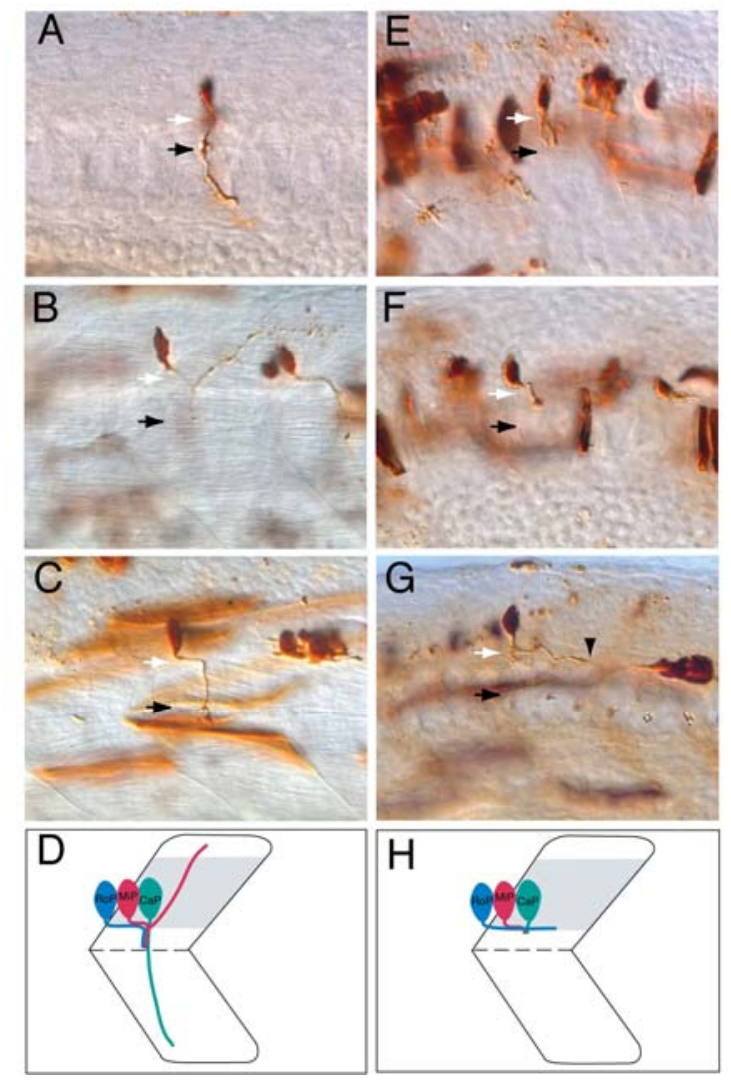

\subsection{Transcriptional Control of Motor Axon Exit}

A variety of TFs have key roles in regulating the pathfinding behavior of ventrally- and dorsally-exiting motor axons, including their exit from the CNS [64]. For example, in Drosophila embryos Nkx6 [14] and Zfh1 [20] are required for vMNs to leave the CNS, whereas, Eve controls the exit of dorsally projecting motor axons (Figures 5, 6 and Table 1) [10]. Supporting a model in which these TFs control motor axon guidance by altering the expression of cell surface effector molecules, Eve and Nkx6 likely regulate the levels of UNC5 [10] and FASIII [14], respectively. In mice lacking both Lhx3 and Lhx4, vMNs adopt a SACMN-like fate and project their axons out of the LEP and, conversely, forced expression of Lhx3 in dMNs re-directs their axons out of the spinal cord through the ventral exit points (Table 1) [4]. Phox $2 \mathrm{~b}$ is also required for dorsal $\mathrm{MN}$ development in mouse 
embryos [22], and, in chick embryos, the mis-expression of Phox2a and Phox $2 \mathrm{~b}$ in interneurons respecifies these neurons to adopt dMN-like fates and forces their axons to ectopically exit the spinal cord through dorsal exit points (Table 1) [17]. We have previously shown that, in mice lacking Nkx2.9; a homeodomain-containing TF that is expressed in the ventral-most neural progenitor domain of the neural tube where it presumably regulates cell fate decisions [65], SACMN axons appropriately reach the LEP, but fail to leave the spinal cord (Table 1) [5]. Taken together, Lhx3/4, Phox2a/b and Nkx2.9 regulate vertebrate $\mathrm{MN} / \mathrm{axon}$ development, at least in part, by controlling the expression of particular cell surface proteins/guidance receptors. However, candidate downstream effectors/targets for these $\mathrm{MN}$-associated TFs have yet to be identified.

Figure 5. $Z f h 1$ is required for a subset of motor axons to emerge from the spinal cord. $(\mathbf{A}, \mathbf{B})$ Flat-mounted zebrafish embryos were labeled with either anti-FASIII $(\mathbf{A , B})$ or anti-myc (C,D) to visualize the axonal projections of an early-developing intersegmental nerve (ISN) called ISNb. Note, ISNb axons selectively express the isl-tau:myc transgene and montages were created by combining images taken from multiple focal planes to visualize the extent of the ISNb nerve. In stage 16 (A) and 15 (C) wild type embryos, zfh1-expressing RP MNs (white asterisk) form an ISNb nerve that extends out and beyond the lateral edge of the CNS (dashed white line). White arrowheads correspond to the terminal end of an ISNb axon. In contrast, a subset of RP MN axons fails to exit the CNS in $z$ fh1 mutants (B,D, top), while others extend appropriately to their peripheral muscle field (B,D, bottom) [20].

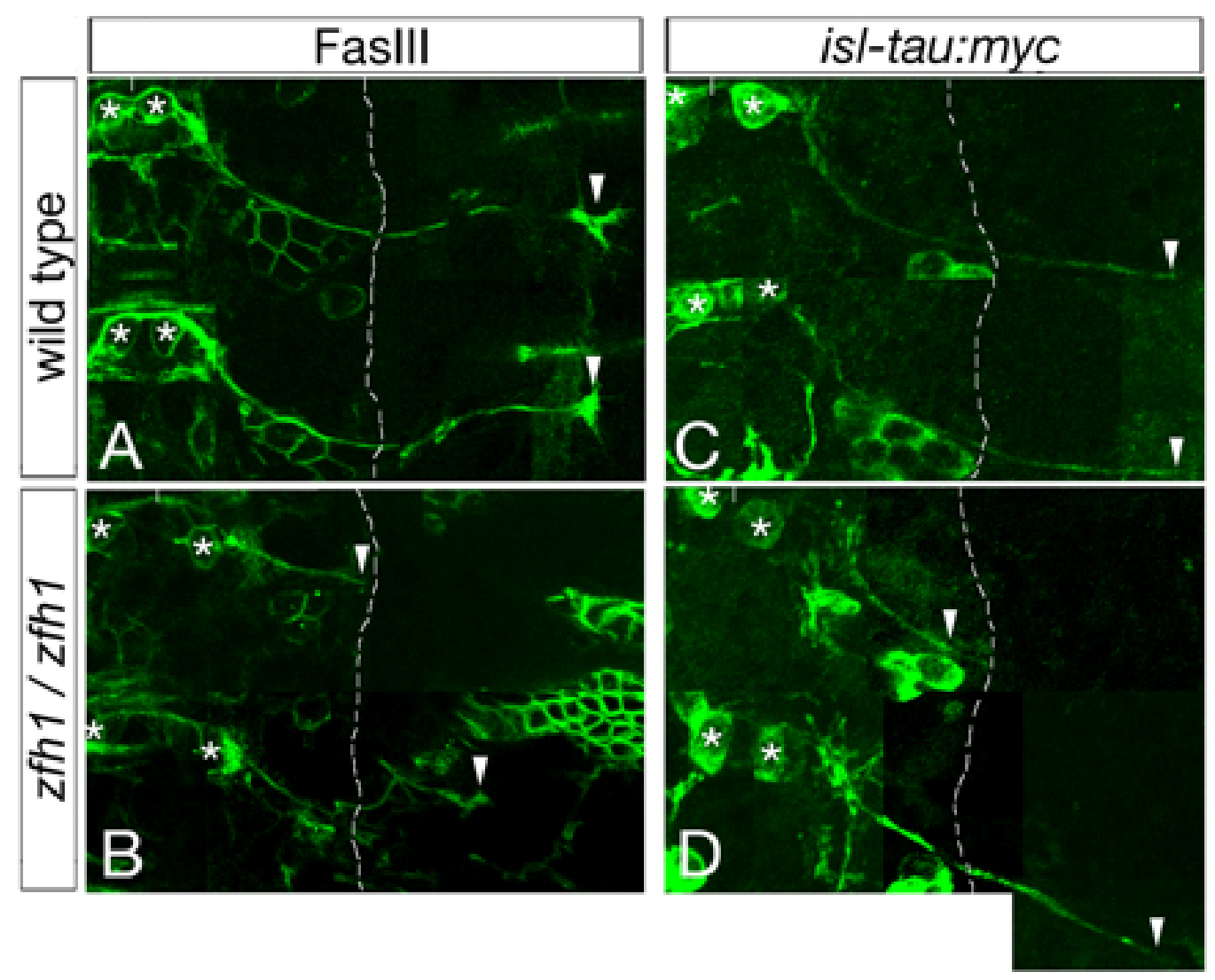


Figure 6. Eve is required for motor axon exit in Drosophila and expression of Unc-5 in eve mosaic mutants restores motor axon exit defects. (A-C) Stage-16 RN2Gal4::CD8GFP embryos of various genotypes, including eve/+ (A), mosaic eve mutant (B), and Unc-5-expressing mosaic eve mutant siblings (RN2Gal4, UAS-HAUnc-5) (C) were labeled with anti-GFP to visualize axons of somatic MNs, aCC and RP2. In eve/+ embryos, aCC and RP2 MNs extend wild type axonal projections to peripheral muscle fields (white arrowheads) (A). In contrast, the majority of aCC and RP2 motor axons fail to leave the CNS (89\%, $n=80$ hemisegments) and instead, inappropriately extend their axons longitudinally within the CNS (white arrows) (B). However, a small subset of motor axons does manage to exit the CNS (open white arrowhead). Notably, expression of Unc-5 in eve mosaic mutants partially rescues the aberrant motor axon exit phenotype $(60 \%$ hemisegments, $n=100$, white arrowheads) (C). In all panels, anterior is at the top of the micrograph [10].
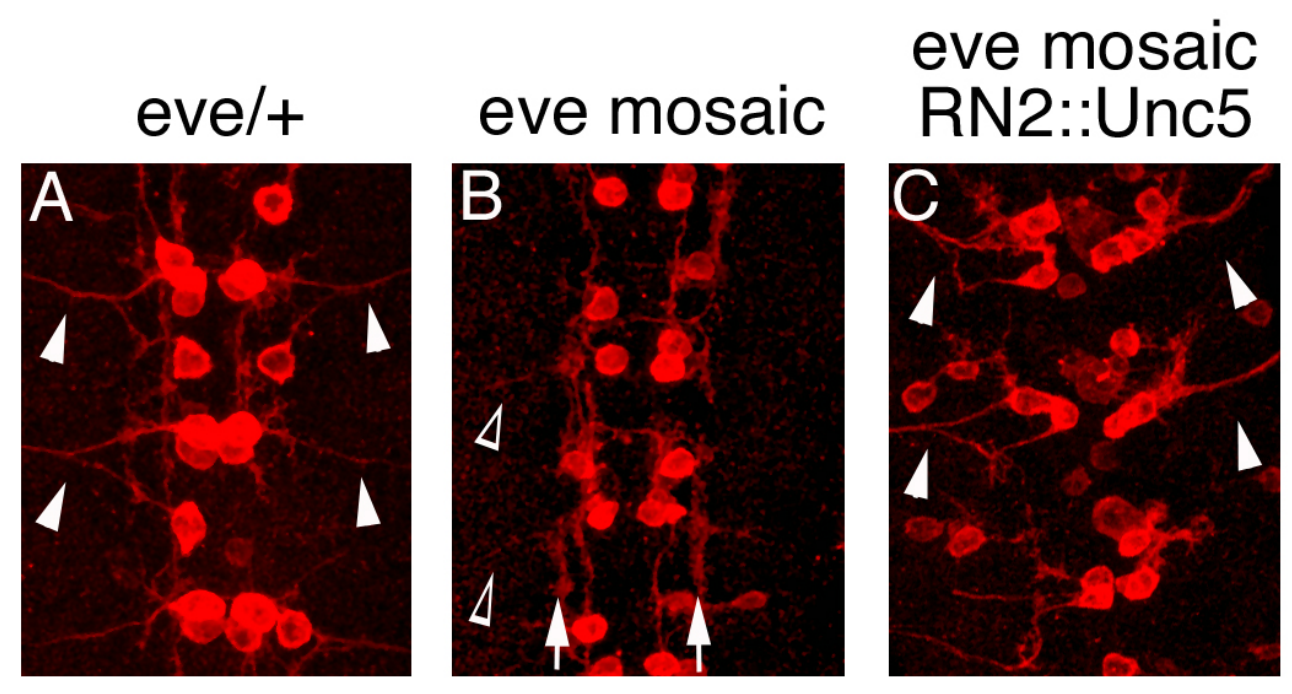

\subsection{Spinal Accessory Motor Neurons (SACMN) as a Model System for Elucidating Mechanisms that Regulate Motor Exit Point-Related Guidance Events}

In contrast to most previous studies that have focused on the pathfinding of ventrally-exiting spinal MNs, we have utilized dorsally-exiting SACMN as a model system for investigating the mechanisms which regulate motor exit-point related axon guidance events. SACMN cell bodies are found at cervical levels of vertebrate embryos and their axons pathfind along a dorsally-directed trajectory away from the ventral midline of the spinal cord to a position located adjacent to the LEP, midway along the D-V axis [5]. Ultimately, SACMN axons exit through a discrete LEP, turn rostrally and assemble into the SAN, which innervates the sternocleidomastoid and trapezius muscles in the neck and back [2-6]. SACMN represent an ideal model system for elucidating the mechanisms that control exit point-related guidance events in vertebrate embryos since: (1) SACMN are a molecularly homogenous population of dMNs; (2) we have previously identified BEN, an immunoglobulin domain-containing cell surface protein as a selective marker of SACMN cell bodies and their axons in rodent embryos [2,5]; (3) SACMN axons are the sole MN axons that project out of the spinal cord through a discrete LEP; and (4) SACMN axons assemble into a readily identifiable longitudinally 
projecting SAN outside of the CNS (Figure 7). Moreover, and as mentioned above, we have previously shown that the homeodomain $\mathrm{TF}, \mathrm{Nkx} 2.9$, is likely required for SACMN axons to project out of the spinal cord [5]. This particular observation prompted us to search for novel downstream effectors of Nkx2.9 that we reasoned might directly facilitate $\mathrm{MN}$ axon exit from the mammalian spinal cord.

Figure 7. SACMN extend dorsally directed axons towards and through the LEP. Schematic illustrating the axonal trajectory of SACMN and the SAN in the developing vertebrate spinal cord. BEN is selectively expressed on SACMN cell bodies and their axons, as well as on the SAN. D, dorsal, V, ventral, A, anterior, P, posterior, LEP-Lateral Exit Point; SAN-Spinal Accessory Nerve.

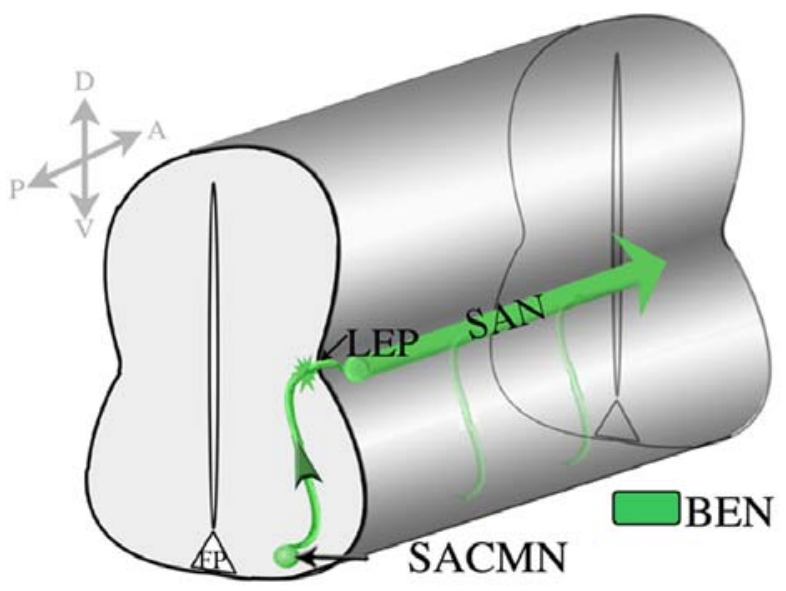

\subsection{The Homeodomain Transcription Factor, Nkx2.9, Controls Motor Axon Exit from the Mouse Spinal Cord via Robo-Slit Signaling}

We performed candidate-based and microarray screens to identify novel downstream effector molecules of Nkx2.9 that regulate SACMN axon exit from the CNS. Our findings suggest that Nkx2.9 selectively controls the exit of SACMN axons from the spinal cord via the regulation of the Robo2 guidance receptor (unpublished observations). Consistent with such a model, our studies indicate that SACMN axons express Robo2, Slits are present at the LEP, and that SACMN axons fail to exit the spinal cord in mice lacking Nkx2.9, Robo2 and/or Slits (Table 1). We have also shown that Robo2-Slit interactions are required for the proper assembly of SACMN axons into the longitudinally projecting SAN, and that SACMN axons do not stall at the LEP, but rather inappropriately form a longitudinal-projecting ectopic nerve within the spinal cord. Whereas previous studies established that Nkx2.9 progenitors are capable of giving rise to interneurons and floor plate cells $[65,66]$, we have shown that they can also generate SACMN within the developing spinal cord, supporting the view that Nkx2.9 acts in a cell autonomous manner to regulate SACMN axon pathfinding.

\subsection{Homeobox Genes and Motor Axon Exit}

Our microarray screen also identified a number of Hox genes that are dysregulated in the absence of Nkx2.9. These findings raise the possibility that multiple homeodomain TFs operate in concert to control 
SACMN axon exit from the spinal cord, perhaps by regulating the expression of Robo2 (see above). Consistent with this hypothesis, Hoxa2 is capable of regulating Robo2 expression in the vertebrate CNS [67]. In support of the possibility that Hox proteins cooperate with Nkx2.9 to regulate SACMN axon exit, we found that among the five Hox genes (Hoxc8, Hoxc6, Hoxd8, Hoxb9, Hoxa6) retrieved from the microarray screen, Hoxb9 expression was selectively reduced in $N k x 2.9$ null mice (data not shown). Specifically, Hoxb9 expression in cells located directly above and adjacent to the FP, a domain normally occupied by Nkx2.9-expressing progenitors is reduced, whereas the levels of HoxC6 appears unaltered (data not shown). These particular findings indicate that Hoxb9 may be a novel putative downstream effector of Nkx2.9. Interestingly, mice with a targeted deletion of the Hoxb1-Hoxb9 locus (Hoxb $\Delta 1$ ) exhibit abnormal fusion of cranial nerves IX and X, a phenotype also observed in Nkx2.9 mutant mice $([65,68]$ and data not shown). Although these mice do not selectively lack Hoxb9, such findings raise the possibility that Hoxb genes are involved in cranial motor nerve development. It is also tempting to speculate that Hoxb9 may be a component of an Nkx2.9-dependent transcriptional program that regulates the projection of SACMN axons out of the CNS.

\section{Perspectives}

Although motor axon exit is a key phase of MN development, our understanding of this phenomenon, and especially the underlying molecular mechanisms that operate in vertebrate systems, is fragmentary at best. Accordingly, there is much to be done with respect to identifying the repertoire of molecules that facilitate the projection of motor axons across the CNS:PNS border. Below, we discuss several of the unresolved issues associated with this indispensable phase of $\mathrm{MN}$ development that must be addressed in future studies, with an emphasis on how motor growth cones might breach the basal lamina surrounding the vertebrate CNS.

\subsection{A Novel Role for Robo-Slit Signaling in Motor Axon Exit}

Although Robo-Slit interactions are well known to regulate a variety of axon guidance events, our findings described above are the first to implicate Robo-Slit signaling in motor axon exit for any model organism [69]. Further, we suggest that attractive or repulsive Robo2-Slit interactions at the LEP may facilitate SACMN axon exit from the spinal cord. Co-culturing SACMN-containing spinal cord explants with LEP-associated tissue would help to differentiate between these two possibilities. Additionally, by co-culturing similar motor explants with a Slit-expressing source it should be possible to determine which Slit(s) evoke a response from Robo2-expressing SACMN axons. It is conceivable that Robo2 facilitates the growth of SACMN axons across a source of LEP-associated Slit via an attractive mechanism. Consistent with this possibility, a positive role for Robo2 in promoting the growth of commissural axons across the Slit-rich midline in the Drosophila ventral nerve cord has recently been reported [70-72]. These particular studies hypothesize that Robo2 acts in an attractive manner to promote midline crossing through a source of Slit, potentially by antagonizing Robo 1 repulsion [70-72]. Although fly Robo2 is not the orthologue of vertebrate Robo2, this does not preclude a role for vertebrate Robo2 in promoting SACMN crossing at the LEP in an attractive manner [73]. In this regard, and by analogy with the role of Robo3 in facilitating midline crossing in the mouse spinal cord, Robo2 might promote SACMN axon exit by repressing the actions of Robo1 [73,74]. Whereas 
SACMN do appear to express Robo1, we failed to observe rescue of SACMN axon exit in mice lacking both Robo1 and Robo2 (data not shown). Accordingly, it seems unlikely that Robo2 antagonizes Robo1 signaling in the context of SACMN axon exit.

Although our studies have focused on a specific population of spinal MNs, they may provide insights into a more general understanding of how sensory and motor axons enter and exit the CNS, respectively. For example, our observations might also be relevant to the molecular logic that controls the exit of other classes of motor axons, distributed all along the A-P axis of the developing CNS, including those residing in the hindbrain. In this regard, it is interesting to note that cranial nerves IX and X appear fused in $N k x 2.9$ null mice ([65] and data not shown).

\subsection{Is There a "Molecular Network" That Controls Motor Axon Exit?}

Given that a number of molecules are likely to regulate motor axon exit-related events in vertebrates, it seems reasonable to suspect that at least a subset of these molecules operate in concert within a specialized network to promote the exit of motor axons from the developing mammalian CNS Notbaly, both Nkx2.9 and myotome-derived LH3 are required for MN axons to exit the spinal cord in vertebrates (data not shown and [11,12]). Accordingly, LH3 expression may be altered in the absence of Nkx2.9, making LH3 a putative downstream effector of Nkx2.9 that directly facilitates SACMN axon exit. Consistent with this hypothesis, $N k x 2.9$ mRNA is expressed by the mesoderm, which is the germ layer that ultimately gives rise to myotome, at a very young age ( E7.0) (see [75], Figure 3(D)). Given that Nkx2.9 and Eve regulate dMN axon exit in vertebrates and Drosophila Melanogaster, respectively, it is also possible that vertebrate homologs of Eve, Evx-1 and/or Evx-2 regulate dMN motor axon exit in mammals. As also noted above, Hox genes were retrieved from our microarray screen, making them good candidates for participating in an Nkx2.9-regulated cascade that promotes SACMN axon exit. Interestingly, vertebrate Hox genes map closely to Evx-1 and Evx-2, raising the possibility that Nkx2.9 controls SACMN axon exit by regulating the expression of these particular transcription factors "in cis" [76-78].

\subsection{Crossing the Basal Lamina Border}

To ultimately emerge from the CNS, motor axons must somehow break through the basal lamina surrounding the neural tube. Although the studies that we have described in this review, including our own, do not directly address the molecular mechanisms underlying this phase of motor axon pathfinding, it is conceivable that cytoskeletal changes in motor axon growth cones facilitate the projection of motor axons through circumscribed exit points (see above). In addition, the release of proteolytic enzymes, such as particular types of proteases, may promote motor axon exit by generating precisely-positioned breaks in the basal lamina. Consistent with this hypothesis, two families of metalloproteases, the A Disintegrin and Metalloproteases (ADAMs) and matrix metalloproteases (MMPs), have been implicated in regulating axon pathfinding in the developing CNS [79]. Notably, a member of the ADAM family, ADAMTS3, was retrieved from our microarray screen and the corresponding mRNA levels appear to be reduced in the absence of Nkx2.9 (data not shown). It is conceivable that SACMN axons express ADAMTS3 to facilitate their exit from the CNS, however, further studies will be required to address this and other possibilities. Taken together, it seems 
plausible that Robo-Slit signaling at the LEP normally triggers the expression of ADAMTS3 which, in turn, facilitates the growth of SACMN axons across the CNS:PNS border.

\subsection{Do Motor Neuron Growth Cones Use Invadopodia to Cross the CNS:PNS Barrier?}

The demonstrated ability of tumor cells to degrade extracellular matrix prompted us to ask whether motor axon growth cones can also function in this manner and, if so, do they utilize the same machinery deployed by invasive cancer cells? It is well-established that cancer cells invade layers of extracellular matrix, a key step in tumor metastasis, by extending small localized protrusions, termed invadopodia, which preferentially degrade matrix [80]. Studies addressing the molecular mechanisms underlying the invasive properties of these cancer cells often employ the so-called "invadopodium degradation assay." This involves plating cells on a culture surface coated with a thin layer of fluorescently-labeled matrix and using fluorescence microscopy to identify regions devoid of fluorescence, which presumably correspond to areas of matrix degraded by the cell [81-84]. As a first step toward determining whether or not MNs are capable of degrading extracellular matrix, we adapted this assay and performed pilot studies by plating neurons derived from the embryonic spinal cord on fluorescent matrix-coated dishes. Our preliminary findings revealed that developing spinal neurons express the invadopodia marker, cortactin, and that these particular cells have the capacity to breakdown extracellular matrix (data not shown). To determine if motor neurons, in particular, are capable of degrading matrix, BEN-, Phox2b- and HB9-expressing MNs can be isolated from the spinal cord of BenGFP, Phox2b-eGFP, and Hb9-GFP mice, respectively, via fluorescence activated cell sorting (FACS) [85-88] and tested in the invadopodia assay. Positive results in these experiments would suggest that tumor cells and embryonic spinal MNs employ similar mechanisms to accomplish a fundamentally similar task, namely the degradation of extracellular matrix, for very different purposes.

\section{Experimental Section}

\subsection{Animals}

Expression studies were performed using E4.5 chick embryos purchased from Charles River Laboratories, Avian Products and Services (SPAFAS).

\subsection{Immunohistochemistry}

Cryosection preparation and immunolabeling. Whole embryos were fixed in 4\% paraformaladehyde (PFA) for $12 \mathrm{~h}$ at $4{ }^{\circ} \mathrm{C}$, followed by cryoprotection in $30 \%$ sucrose in $4{ }^{\circ} \mathrm{C}$ until embryos sank to the bottom of the tube. Embryos were then embedded in optimal cutting temperature compound (Tissue Tek; Sakura Finetek) and stored in the $-20^{\circ} \mathrm{C}$. Cryosections $(16 \mu \mathrm{m})$ were generated using a Leica cryostat (model \#; CM3050 S; Leica Microsystems) and collected on Superfrost Plus microscope slides (Fisher Scientific, Cat. No. 12-550-15). Transverse cryosections were rinsed in PBS, post-fixed for $10 \mathrm{~min}$, washed with PBS $1 \times 5$ min, and incubated for $1 \mathrm{~h}$ in blocking solution. Sections were subsequently incubated with primary antibody diluted in blocking solution $\mathrm{O} / \mathrm{N}$ in $4{ }^{\circ} \mathrm{C}$. Following primary antibody incubation, sections were washed $3 \times 10 \mathrm{~min}$ in blocking solution, incubated with the appropriate 
secondary antibodies, for $1 \mathrm{~h}$, and washed $3 \times 10$ min with blocking solution. The following antibodies were used in this study: anti-BEN/SC1 (DSHB), anti-Cadherin 7 (DSHB), and anti-NF (Sigma).

\subsection{Photodocumentation}

Primary antibody binding was visualized using conventional epifluorescence microscopy (Nikon Eclipse TE300) and images were captured with a digital camera (Optronics) and compatible Magnafire software [5]. In all cases, composites were assembled and annotated using Adobe Photoshop CS3.

\section{Acknowledgments}

The monoclonal antibodies specific for BEN/SC-1 (Le Douarin, N. and Pourquie, O.) Cadherin 7 (Takeichi, M. and Nakagawa, S.), and Islet-1 (Jessell, T.M. and Brenner-Morton, S.) were obtained from the Developmental Studies Hybridoma Bank developed under the auspices of the NICHD and maintained by The University of Iowa, Department of Biology, Iowa City, IA 52242. Various aged Krox $20^{D T}$ and wild type embryos were a kind gift from P. Topilko (Ecole Normale Supérieure, Paris, France; [29]. Work from the Kaprielian lab was supported by National Institutes of Health (NIH) grants R56NS038505, R01NS038505 (Z.K.). A.B.-A. was supported by Einstein's MSTP, Edward A. and Lucille Kimmel Scholarship, and SFN's Neuroscience Scholars Program.

\section{References}

1. Cordes, S.P. Molecular genetics of cranial nerve development in mouse. Nat. Rev. Neurosci. 2001, 2, 611-623.

2. Schubert, W.; Kaprielian, Z. Identification and characterization of a cell surface marker for embryonic rat spinal accessory motor neurons. J. Comp. Neurol. 2001, 439, 368-383.

3. Snider, W.D.; Palavali, V. Early axon and dendritic outgrowth of spinal accessory motor neurons studied with DiI in fixed tissues. J. Comp. Neurol. 1990, 297, 227-238.

4. Sharma, K.; Sheng, H.Z.; Lettieri, K.; Li, H.; Karavanov, A.; Potter, S.; Westphal, H.; Pfaff, S.L. LIM homeodomain factors Lhx3 and Lhx4 assign subtype identities for motor neurons. Cell 1998, 95, 817-828.

5. Dillon, A.K.; Fujita, S.C.; Matise, M.P.; Jarjour, A.A.; Kennedy, T.E.; Kollmus, H.; Arnold, H.-H.; Weiner, J.A.; Sanes, J.R.; Kaprielian, Z. Molecular control of spinal accessory motor neuron/axon development in the mouse spinal cord. J. Neurosci. 2005, 25, 10119-10130.

6. Lieberam, I.; Agalliu, D.; Nagasawa, T.; Ericson, J.; Jessell, T.M. A Cxcl12-Cxcr4 chemokine signaling pathway defines the initial trajectory of mammalian motor axons. Neuron 2005, 47, 667-679.

7. Chandrasekhar, A. Turning heads: Development of vertebrate branchiomotor neurons. Dev. Dyn. 2004, 229, 143-161.

8. Guthrie, S. Patterning and axon guidance of cranial motor neurons. Nat. Rev. Neurosci. 2007, 8, 859-871.

9. Fritzsch, B.; Northcutt, R.G. Cranial and spinal nerve organization in amphioxus and lampreys: Evidence for an ancestral craniate pattern. Acta Anat. (Basel) 1993, 148, 96-109. 
10. Labrador, J.P.; O’Keefe, D.; Yoshikawa, S.; McKinnon, R.D.; Thomas, J.B.; Bashaw, G.J. The homeobox transcription factor even-skipped regulates netrin-receptor expression to control dorsal motor-axon projections in Drosophila. Curr. Biol. 2005, 15, 1413-1419.

11. Schneider, V.A.; Granato, M. The myotomal diwanka (lh3) glycosyltransferase and type XVIII collagen are critical for motor growth cone migration. Neuron 2006, 50, 683-695.

12. Zeller, J.; Granato, M. The zebrafish diwanka gene controls an early step of motor growth cone migration. Development 1999, 126, 3461-3472.

13. Murray, A.; Naeem, A.; Barnes, S.H.; Drescher, U.; Guthrie, S. Slit and Netrin-1 guide cranial motor axon pathfinding via Rho-kinase, myosin light chain kinase and myosin II. Neural. Dev. 2010, 5, 16-30.

14. Broihier, H.T.; Kuzin, A.; Zhu, Y.; Odenwald, W.; Skeath, J.B. Drosophila homeodomain protein Nkx6 coordinates motoneuron subtype identity and axonogenesis. Development 2004, 131, 5233-5242.

15. Sato-Maeda, M.; Obinata, M.; Shoji, W. Position fine-tuning of caudal primary motoneurons in the zebrafish spinal cord. Development 2008, 135, 323-332.

16. Bron, R.; Vermeren, M.; Kokot, N.; Little, G.E.; Mitchell, K.J.; Andrews, W.; Cohen, J. Boundary cap cells constrain spinal motor neuron somal migration at motor exit points by a semaphorin-plexin mechanism. Neural. Dev. 2007, 2, 21-39.

17. Hirsch, M.-R.; Glover, J.C.; Dufour, H.D.; Brunet, J.-F.; Goridis, C. Forced expression of Phox2 homeodomain transcription factors induces a branchio-visceromotor axonal phenotype. Dev. Biol. 2007, 303, 687-702.

18. Mauti, O.; Domanitskaya, E.; Andermatt, I.; Sadhu, R.; Stoeckli, E.T. Semaphorin6A acts as a gate keeper between the central and peripheral nervous system. Neural. Dev. 2007, 2, 28-44.

19. Palaisa, K.A.; Granato, M. Analysis of zebrafish sidetracked mutants reveals a novel role for Plexin A3 in intraspinal motor axon guidance. Development 2007, 134, 3251-3257.

20. Layden, M.J.; Odden, J.P.; Schmid, A.; Garces, A.; Thor, S.; Doe, C.Q. Zfh1, a somatic motor neuron transcription factor, regulates axon exit from the CNS. Dev. Biol. 2006, 291, 253-263.

21. Dillon, A.K.; Jevince, A.R.; Hinck, L.; Ackerman, S.L.; Lu, X.; Tessier-Lavigne, M.; Kaprielian, Z. UNC5C is required for spinal accessory motor neuron development. Mol. Cell. Neurosci. 2007, 35, 482-489.

22. Pattyn, A.; Hirsch, M.-R.; Goridis, C.; Brunet, J.-F. Control of hindbrain motor neuron differentiation by the homeobox gene Phox2b. Development 2000, 127, 1349-1358.

23. Song, M.-R.; Shirasaki, R.; Cai, C.-L.; Ruiz, E.C.; Evans, S.M.; Lee, S.-K.; Pfaff, S.L. T-box transcription factor $\mathrm{Tbx} 20$ regulates a genetic program for cranial motor neuron cell body migration. Development 2006, 133, 4945-4955.

24. Arber, S.; Han, B.; Mendelsohn, M.; Smith, M.; Jessell, T.; Sockanathan, S. Requirement for the homeobox gene Hb9 in the consolidation of motor neuron identity. Neuron 1999, 23, 659-674.

25. Shirasaki, R.; Pfaff, S.L. Transcriptional codes and the control of neuronal identity. Ann. Rev. Neurosci. 2002, 25, 251-281.

26. Jacob, J.; Hacker, A.; Guthrie, S. Mechanisms and molecules in motor neuron specification and axon pathfinding. BioEssays 2001, 23, 582-595.

27. Schneider, V.A.; Granato, M. Motor axon migration: A long way to go. Dev. Biol. 2003, 263, 1-11. 
28. Niederlander, C.; Lumsden, A. Late emigrating neural crest cells migrate specifically to the exit points of cranial branchiomotor nerves. Development 1996, 122, 2367-2374.

29. Vermeren, M.; Maro, G.S.; Bron, R.; McGonnell, I.M.; Charnay, P.; Topilko, P.; Cohen, J. Integrity of developing spinal motor columns is regulated by neural crest derivatives at motor exit points. Neuron 2003, 37, 403-415.

30. Golding, J.P.; Cohen, J. Border controls at the mammalian spinal cord: Late-surviving neural crest boundary cap cells at dorsal root entry sites may regulate sensory afferent ingrowth and entry zone morphogenesis. Mol. Cell. Neurosci. 1997, 5, 381-396.

31. Wilkinson, D.G.; Bhatt, S.; Chavrier, P.; Bravo, R.; Charnay, P. Segment-specific expression of a zinc-finger gene in the developing nervous system of the mouse. Nature 1989, 337, 461-464.

32. Topilko, P.; Schneider-Maunoury, S.; Levi, G.; Evercooren, A.B.-V.; Chennoufi, A.B.Y.; Seitanidou, T.; Babinet, C.; Charnay, P. Krox-20 controls myelination in the peripheral nervous system. Nature 1994, 371, 796-799.

33. Redies, C. Cadherins in the central nervous system. Prog. Neurobiol. 2000, 61, 611-648.

34. Nakagawa, S.; Takeichi, M. Neural crest emigration from the neural tube depends on regulated cadherin expression. Development 1998, 125, 2963-2971.

35. Okafuji, T.; Tanaka, H. Expression pattern of LINGO-1 in the developing nervous system of the chick embryo. Gene Expr. Patterns 2005, 6, 57-62.

36. Knabe, W.; Siren, A.L.; Ehrenreich, H.; Kuhn, H.J. Expression patterns of erythropoietin and its receptor in the developing spinal cord and dorsal root ganglia. Anat. Embryol. (Berl) 2005, 210, 209-219.

37. Vitalis, T.; Alvarez, C.; Chen, K.; Shih, J.C.; Gaspar, P.; Cases, O. Developmental expression pattern of monoamine oxidases in sensory organs and neural crest derivatives. J. Comp. Neurol. 2003, 464, 392-403.

38. Auerbach, R. Analysis of developmental effects of a lethal mutation in the house mouse. J. Exp. Zool. 1954, 127, 305-329.

39. Henderson, D.J.; Ybot-Gonzalez, P.; Copp, A.J. Overexpression of the chondroitin sulphate proteoglycan versican is associated with defective neural crest migration in the Pax3 mutant mouse (splotch). Mech. Dev. 1997, 69, 39-51.

40. Serbedzija, G.N.; McMahon, A.P. Analysis of neural crest cell migration in Splotch mice using a neural crest-specific LacZ reporter. Dev. Biol. 1997, 185, 139-147.

41. Chauvet, S.; Rougon, G. Semaphorins deployed to repel cell migrants at spinal cord borders. J. Biol. 2008, 7, 4:1-4:5.

42. Fraher, J.P.; Dockery, P.; O’Donoghue, O.; Riedewald, B.; O’Leary, D. Initial motor axon outgrowth from the developing central nervous system. J. Anat. 2007, 211, 600-611.

43. Fraher, J.P.; Rossiter, J.P. Cell clusters on fetal rat ventral roots: Prenatal development. J. Anat. 1983, 136, 111-128.

44. Colamarino, S.A.; Tessier-Lavigne, M. The axonal chemoattractant Netrin-1 is also a chemorepellent for trochlear motor axons. Cell 1995, 81, 621-629.

45. Chang, S.; Fan, J.; Nayak, J. Pathfinding by cranial nerve VII (facial) motor neurons in the chick hindbrain. Development 1992, 114, 815-823. 
46. Caton, A.; Hacker, A.; Naeem, A.; Livet, J.; Maina, F.; Bladt, F.; Klein, R.; Birchmeier, C.; Guthrie, S. The branchial arches and HGF are growth-promoting and chemoattractant for cranial motor axons. Development 2000, 127, 1751-1760.

47. Guthrie, S.; Lumsden, A. Motor neuron pathfinding following rhombomere reversals in the chick embryo hindbrain. Development 1992, 114, 663-673.

48. Shirasaki, R.; Lewcock, J.W.; Lettieri, K.; Pfaff, S.L. FGF as a target-derived chemoattractant for developing motor axons genetically programmed by the LIM code. Neuron 2006, 50, 841-853.

49. Ebens, A.; Brose, K.; Leonardo, E.D.; Hanson, M.G.; Bladt, F.; Birchmeier, C.; Barres, B.A.; Tessier-Lavigne, M. Hepatocyte growth factor/scatter factor is an axonal chemoattractant and a neurotrophic factor for spinal motor neurons. Neuron 1996, 17, 1157-1172.

50. Naeem, A.; Abbas, L.; Guthrie, S. Comparison of the effects of HGF, BDNF, CT-1, CNTF, and the brachial arches on the growth of embryonic cranial motor neurons. J. Neurobiol. 2002, 51, 101-114.

51. McCaig, C.D. Myoblasts and myoblast-conditioned medium attract the earliest spinal neurites from frog embryos. J. Physiol. 1986, 375, 39-54.

52. Pollack, E.D.; Muhlach, W.L.; Liebig, V. Neurotrophic influence of mesenchymal limb target tissue on spinal cord neurite growth in vitro. J. Comp. Neurol. 1981, 200, 393-405.

53. Tucker, K.L.; Meyer, M.; Barde, Y.A. Neurotrophins are required for nerve growth during development. Nat. Neurosci. 2001, 4, 29-37.

54. Guthrie, S.; Lumsden, A. Motor neuron pathfinding following rhombomere reversals in the chick embryo hindbrain. Development 1992, 114, 663-673.

55. Irving, C.; Malhas, A.; Guthrie, S.; Mason, I. Establishing the trochlear motor axon trajectory: Role of the isthmic organiser and Fgf8. Development 2002, 129, 5389-5398.

56. Birely, J.; Schneider, V.A.; Santana, E.; Dosch, R.; Wagner, D.S.; Mullins, M.C.; Granato, M. Genetic screens for genes controlling motor nerve-muscle development and interactions. Dev. Biol. 2005, 280, 162-176.

57. Kucenas, S.; Takada, N.; Park, H.C.; Woodruff, E.; Broadie, K.; Appel, B. CNS-derived glia ensheath peripheral nerves and mediate motor root development. Nat. Neurosci. 2008, 11, 143-151.

58. Kucenas, S.; Wang, W.D.; Knapik, E.W.; Appel, B. A selective glial barrier at motor axon exit points prevents oligodendrocyte migration from the spinal cord. J. Neurosci. 2009, 29, 15187-15194.

59. Hammond, R.; Vivancos, V.; Naeem, A.; Chilton, J.; Mambitisaeva, E.; Andrews, W.; Sundaresan, V.; Guthrie, S. Slit-mediated repulsion is a key regulator of motor axon pathfinding in the hindbrain. Development 2005, 132, 4483-4495.

60. Colamarino, S.A.; Tessier-Lavigne, M. The role of the floor plate in axon guidance. Ann. Rev. Neurosci. 1995, 18, 497-529.

61. Burgess, R.W.; Jucius, T.J.; Ackerman, S.L. Motor axon guidance of the mammalian trochlear and phrenic neves: Dependence on the netrin receptor Unc5c and modifier loci. J. Neurosci. 2006, 26, 5756-5766.

62. Brown, J.; Bridgman, P.C. Role of myosin II in axon outgrowth. J. Histochem. Cytochem. 2003, 51, 421-428. 
63. Zeller, J.; Schneider, V.; Malayaman, S.; Higashijima, S.; Okamoto, H.; Gui, J.; Lin, S.; Granato, M. Migration of zebrafish spinal motor nerves into the periphery requires multiple myotome-derived cues. Dev. Biol. 2002, 252, 241-256.

64. Butler, S.J.; Tear, G. Getting axons onto the right path: The role of transcription factors in axon guidance. Development 2007, 134, 439-448.

65. Pabst, O.; Rummelies, J.; winter, B.; Arnold, H.-H. Targeted disruption of the homeobox gene Nkx2.9 reveals a role in development of the spinal accessory nerve. Development 2003, 130, 1193-1202.

66. Holz, A.; Kollmus, H.; Ryge, J.; Niederkofler, V.; Dias, J.; Ericson, J.; Stoeckli, E.T.; Kiehn, O.; Arnold, H.H. The transcription factors $\mathrm{Nkx} 2.2$ and $\mathrm{Nkx} 2.9$ play a novel role in floor plate development and commissural axon guidance. Development 2010, 137, 4249-4260.

67. Geisen, M.J.; Di Meglio, T.; Pasqualetti, M.; Ducret, S.; Brunet, J.F.; Chedotal, A.; Rijli, F.M. Hox paralog group 2 genes control the migration of mouse pontine neurons through slit-robo signaling. PLoS Biol. 2008, 6, e142:1178-e142:1194.

68. Medina-Martinez, O.; Bradley, A.; Ramirez-Solis, R. A large targeted deletion of Hoxb1-Hoxb9 produces a series of single-segment anterior homeotic transformations. Dev. Biol. 2000, 222, 71-83.

69. Ypsilanti, A.R.; Zagar, Y.; Chedotal, A. Moving away from the midline: New developments for Slit and Robo. Development 2010, 137, 1939-1952.

70. Spitzweck, B.; Brankatschk, M.; Dickson, B.J. Distinct protein domains and expression patterns confer divergent axon guidance functions for Drosophila Robo receptors. Cell 2010, 140, 409-420.

71. Pappu, K.S.; Zipursky, S.L. Axon guidance: Repulsion and attraction in roundabout ways. Curr. Biol. 2010, 20, R400-R402.

72. Evans, T.A.; Bashaw, G.J. Functional diversity of Robo receptor immunoglobulin domains promotes distinct axon guidance decisions. Curr. Biol. 2010, 20, 567-572.

73. Dickson, B.J.; Gilestro, G.F. Regulation of commissural axon pathfinding by Slit and its Robo receptors. Annu. Rev. Cell. Dev. Biol. 2006, 22, 651-675.

74. Sabatier, C.; Plump, A.S.; Ma, L.; Brose, K.; Tamada, A.; Murakami, F.; Lee, E.Y.-H.P.; Tessier-Lavigne, M. The divergent Robo family protein Rig-1/Robo3 is a negative regulator of Slit responsiveness required for midline crossing by commissural axons. Cell 2004, 117, 157-169.

75. Pabst, O.; Herbrand, H.; Arnold, H.H. Nkx2-9 is a novel homeobox transcription factor which demarcates ventral domains in the developing mouse CNS. Mech. Dev. 1998, 73, 85-93.

76. Sordino, P.; Duboule, D.; Kondo, T. Zebrafish Hoxa and Evx-2 genes: Cloning, developmental expression and implications for the functional evolution of posterior Hox genes. Mech. Dev. 1996, 59, 165-175.

77. Dolle, P.; Fraulob, V.; Duboule, D. Developmental expression of the mouse Evx-2 gene: Relationship with the evolution of the HOM/Hox complex. Dev. Suppl. 1994, 143-153.

78. Bastian, H.; Gruss, P.; Duboule, D.; Izpisua-Belmonte, J.C. The murine even-skipped-like gene Evx-2 is closely linked to the Hox-4 complex, but is transcribed in the opposite direction. Mamm. Genome 1992, 3, 241-243.

79. McFarlane, S. Metalloproteases: Carving out a role in axon guidance. Neuron 2003, 37, 559-562. 
80. Weaver, A.M. Invadopodia: Specialized cell structures for cancer invasion. Clin. Exp. Metastasis 2006, 23, 97-105.

81. Chen, W.T. Proteolytic activity of specialized surface protrusions formed at rosette contact sites of transformed cells. J. Exp. Zool. 1989, 251, 167-185.

82. Oser, M.; Condeelis, J. The cofilin activity cycle in lamellipodia and invadopodia. J. Cell. Biochem. 2009, 108, 1252-1262.

83. Oser, M.; Yamaguchi, H.; Mader, C.C.; Bravo-Cordero, J.J.; Arias, M.; Chen, X.; Desmarais, V.; van Rheenen, J.; Koleske, A.J.; Condeelis, J. Cortactin regulates cofilin and N-WASp activities to control the stages of invadopodium assembly and maturation. J. Cell. Biol. 2009, 186, 571-587.

84. Oser, M.; Mader, C.C.; Gil-Henn, H.; Magalhaes, M.; Bravo-Cordero, J.J.; Koleske, A.J.; Condeelis, J. Specific tyrosine phosphorylation sites on cortactin regulate Nck1-dependent actin polymerization in invadopodia. J. Cell. Sci. 2010, 123, 3662-3673.

85. Weiner, J.A.; Koo, S.J.; Nicolas, S.; Fraboulet, S.; Pfaff, S.L.; Pourquie, O.; Sanes, J.R. Axon fasciculation defects and retinal dysplasias in mice lacking the immunoglobulin superfamily adhesion molecule BEN/ALCAM/SC1. Mol. Cell. Neurosci. 2004, 27, 59-69.

86. Lee, S.-K.; Jurata, L.W.; Funahashi, J.; Ruiz, E.C.; Pfaff, S.L. Analysis of embryonic motoneuron gene regulation: Derepression of general activators function in concert with enhancer factors. Development 2004, 131, 3295-3306.

87. Wichterle, H.; Lieberam, I.; Porter, J.A.; Jessell, T.M. Directed differentiation of embryonic stem cells into motor neurons. Cell 2002, 110, 385-397.

88. Lazarenko, R.M.; Milner, T.A.; Depuy, S.D.; Stornetta, R.L.; West, G.H.; Kievits, J.A.; Bayliss, D.A.; Guyenet, P.G. Acid sensitivity and ultrastructure of the retrotrapezoid nucleus in Phox2b-EGFP transgenic mice. J. Comp. Neurol. 2009, 517, 69-86.

(C) 2011 by the authors; licensee MDPI, Basel, Switzerland. This article is an open access article distributed under the terms and conditions of the Creative Commons Attribution license (http://creativecommons.org/licenses/by/3.0/). 